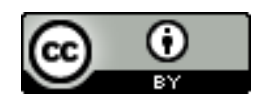

Esta obra está sob o direito de Licença Creative Commons Atribuição 4.0 Internacional.

\title{
PRÁTICAS DE MULTILETRAMENTOS NA ESCOLA: POR UMA EDUCAÇÃO RESPONSIVA À CONTEMPORANEIDADE
}

\author{
Michelly Cristina Apolinário de Lucena ${ }^{1}$ \\ Jayra dos Santos Costa Rocha ${ }^{2}$ \\ Maria das Graças Sandes de Araújo ${ }^{3}$ \\ Magna Valéria dos Santos Melo ${ }^{4}$ \\ Nadson Ribeiro ${ }^{5}$ \\ Silvânia Marques de Almeida 6
}

\section{RESUMO}

$\mathrm{O}$ artigo mostra a importância da atitude responsiva às demandas educacionais da contemporaneidade deve se voltar para uma formação de professores que os capacite a navegar por práticas de letramentos Inter/transdisciplinares. No que tange ao contexto do ensino de línguas, é primordial proporcionar ambientes de formação docente que estimulem os professores a refletir acerca de suas atividades de trabalho (incluindo aí os materiais didáticos digitais) e a tomar consciência das propriedades efetivas e potenciais dos gêneros textuais/discursivos - instrumentos que medeiam a apropriação dos saberes linguísticodiscursivos de referência necessários para agir nos contextos sociais.

Palavras-chave: Multiletramentos; Responsividade; Ato responsável; Formação.

\section{SUMMARY}

The article shows the importance of the responsive attitude to the educational demands of the contemporaneity should turn to a training of teachers that will enable them to navigate through inter / transdisciplinary literacy practices. With regard to the context of language teaching, it is essential to provide teacher training environments that stimulate teachers to reflect on their work activities (including digital didactic materials) and to become aware of the effective and potential properties of textual / discursive genres - instruments that mediate the appropriation of the linguistic-discursive knowledge needed to act in contexts social policies.

KEY WORDS: Multiletramentos; Responsiveness; Responsible act; Formation.

\footnotetext{
1 michellyt_pc@hotmail.com

2 jayra_costa@hotmail.com

3 gsandes.sandes@gmail.com

4 mayleid@hotmail.com

5 ribeironadson@hotmail.com

${ }^{6}$ silvania.maqrques.aa@hotmail.com
} 


\section{INTRODUÇÃO}

A partir da compreensão de que a filosofia da linguagem do Círculo de Bakhtin possui a leveza de pensamento e plasticidade necessárias para compreensão e análise das práticas de multiletramentos na contemporaneidade (ROJO, 2013), este artigo propõe-se a bakhtinianamente, refletir sobre os significados de educar como ato responsável. Para tal, revisita a problemática da formação de professores na contemporaneidade em relação aos saberes docentes e sua responsabilidade ética, busca nos diálogos entre concepções do Círculo como ideologia, dialogismo, gênero, hibridismo, responsividade, ato responsável, entre outras, concepções sobre saberes docentes, visões de língua e linguagem (re)desenhadas em diálogos profícuos entre uma vertente indisciplinar da Linguística Aplicada (MOITA LOPES, 2006, 2010, 2013) e a pedagogia dos multiletramentos proposta pelo Grupo de Nova Londres (COPE; KALANTIZIS et al, 2000) discutir o significado de ser professor de linguagens nos tempos atuais.

Inserimos essa discussão no campo de uma Linguística Aplicada que objetiva desenvolver estudos que investiguem a produção e construção de um conhecimento passível de dar visibilidade às questões de linguagem que afetam a vida social (MOITA LOPES, 2006) em uma contemporaneidade que, sob a influência da revolução tecnológica e da mídia, vem assumindo características bem marcantes e em alguns casos bem diversas das formações sociais que a antecederam. Em resumo, uma sociedade globalizada, organizada em redes, que faz avançar estudos relacionados à vida dos seres humanos como, por exemplo, os avanços dos estudos genéticos e as novas tecnologias, rompendo as fronteiras espaciais e temporais e que paradoxalmente assumem, muitas vezes, sua natureza excludente.

Pensando em um cenário no qual o conhecimento surge como elemento constitutivo e identificador dos tempos atuais (STEHR, 2000), pode-se dizer que o conhecimento docente exigido na contemporaneidade deveria apresentar uma natureza múltipla, inter/transdisciplinar, situando-se entre fronteiras, demandando das práticas pedagógicas realizadas em salas de aula uma noção de linguagem também múltipla, complexa, uma heteroglossia axiologizada, como diz Faraco (2009), ao interpretar o pensamento bakhtiniano. Como tornar-se professor em uma sociedade marcada por rupturas, mudanças? Como realizar um trabalho docente com as linguagens no sentido de contribuir com a construção de sujeitos capazes de transitar, compreendendo, 
interpretando e respondendo, a partir de posicionamentos valorados, (a)os discursos produzidos e circulantes nessa sociedade?

Entendemos que múltiplas são as respostas e os caminhos para tal realização. Em meio a essa multiplicidade, vale destacar a necessidade da construção de uma política para o ensino que abra espaço para uma concepção de linguagem/língua voltada para o acontecimento discursivo, configurado em enunciados inacabados, irrepetíveis, cujo funcionamento não se dá pela estrutura, mas em rede e que articule esse ensino e o processo de formação docente, atentando para as exigências de uma educação linguística que oriente a formação de profissionais responsáveis e responsivos (OLIVEIRA, 2008; SZUNDY, 2014).

Tendo o dialogismo como sua premissa central, o Círculo de Bakhtin construiu uma filosofia da linguagem inacabada, suficientemente plástica para se misturar com outras teorias preocupadas em compreender os usos situados da linguagem que (des/re) constroem significados no existir-evento sem álibi (BAKHTIN, 2010),

\section{MATERIAL E MÉTODOS}

Este estudo é uma pesquisa bibliográfica, onde a busca dos artigos a serem analisados foi realizada nas bases de dados BVS, Scielo e Google Acadêmico. A significados estes que trazem implicações éticas para todos aqueles que participam da vida social. Por defender que educadores e aprendizes tornem-se participantes ativos na busca de mudanças sociais, de desenhos de outros futuros a partir da multiplicidade de mídias, culturas e linguagens que caracterizam a vida na contemporaneidade (COPE; KALANTIZIS, 2000), defendemos que a pedagogia dos multiletramentos do Grupo de Nova Londres pode se hibridizar com as concepções de linguagem do Círculo e com a visão de Linguística Aplicada indisciplinar/transgressiva (MOITA LOPES, 2006; PENNYCOOK, 2006), na busca de uma formação de professores de linguagens responsiva e crítica à contemporaneidade.

Com o intuito de contribuir para as discussões sobre essa formação, subdividimos esse artigo em quatro seções: 1. Sobre os saberes docentes; 2. Sobre as noções de linguagem e de língua; 3. Sobre uma pedagogia dos multiletramentos e 4 . Por uma formação de professores de linguagens como ato responsável.

escolha dessas bases de dados justificou-se por ser gratuita e de livre acesso e também pela crescente relevância que o Google vem adquirindo na difusão da produção acadêmica (DINIZ, 2012). 


\section{Sobre os saberes docentes}

A discussão sobre a noção de saberes ou do conhecimento tem se constituído em objeto de reflexão de vários pensadores. Entre eles, destacamos as ideias de Santos (2007) e sua crítica ao modo de pensar a produção do conhecimento na modernidade clássica, permeado, segundo ele, por uma "sociologia das ausências", pelo fato de considerar que o único saber rigoroso seria o saber científico. Um modo de pensar, diz esse autor, que se ancora na linearidade da história, na naturalização das diferenças, na ideia da hegemonia do que é global e universal, conduzindo a uma visão monocultura do saber. Sua proposta é de substituir essa perspectiva por uma "ecologia dos saberes", que se configuraria por fazer dialogar com o saber científico com outras formas de saber, por romper com a linearidade e por apontar para o processo de descolonização de mentes no sentido de possibilitar o reconhecimento daquilo que nas diferenças é ou não produto da hierarquia. Como diz Geraldi (2003), reconhecer as diferenças que resultam e produzem desigualdades.

No caso específico da formação docente no Brasil, Gatti (2010) afirma que o cenário que se apresenta com relação aos saberes docentes, é preocupante, merecendo atenção, entre outras, as ambiguidades existentes na legislação normativa, a fragmentação dos processos formativos e a formação específica para o trabalho docente.

Tardif (2002) também aponta para uma dicotomia entre formação pedagógica e específica, pondo em evidência a falta de projetos globais com relação à formação do professor, questionando a lógica conteudista dos saberes docentes, em geral, limitada à transmissão de conhecimentos consagrados.

Explorando conceitualmente a noção do que sejam saberes docentes, Tardiff (2000) afirma que esse saber é um saber plural, constituído de saberes disciplinares, saberes curriculares, saberes profissionais e saberes da experiência. Os saberes disciplinares correspondem às diversas áreas do conhecimento; os saberes curriculares dizem respeito aos conhecimentos relacionados à organização dos conteúdos e sua distribuição nos diversos níveis de ensino; os profissionais remetem para a relação social e ética com o próprio trabalho; e aqueles da experiência, dizem respeito à vivência dos docentes em seu cotidiano de sala de aula, sendo uma de suas particularidades articular essa vivência com os saberes disciplinares, tornando-se, nesse processo, elementos relevantes para o sucesso ou insucesso escolar.

No campo específico do discurso pedagógico, já afirmava Nóvoa (1995) que 
os professores constroem suas identidades por referência aos saberes teóricos e práticos, presentes em seus quadros de referência, e por adesão a um conjunto de valores. Nesse sentido é que a identidade profissional dos professores não é algo fixo, muito menos uma propriedade, e sim o espaço de conflitos, construção e desconstrução de maneiras de ser e de estar na profissão.

Como tão bem diz Nóvoa (1995), é preciso repensar o que diz este professor, sua voz sobre o contexto marginalizado no qual ele se situa. A construção de professores críticos, reflexivos, intelectuais capacitados e engajados, conduz a uma visão de formação de professores que avança na construção de um processo, na busca da superação das modas que invadem o terreno educativo, as quais, devido à impressionante produção de ideias e à velocidade quase delirante das inovações tecnológicas, estão sempre exigindo atualizações permanentes.

Nóvoa (apud SEGANFREDO, 2012) retoma essa sua reflexão, afirmando que vivemos um tempo de muita inovação nas palavras e de pouca mudança na realidade concreta dos professores e da formação docente. Mais do que nunca seria necessário, diz ele, avançar para novas experiências de formação, considerando a docência e seu exercício sempre como uma resposta contextualizada, diferente de uma sala de aula para outra, de um aluno para outro.

O fato é que os saberes docentes constitutivos do conhecimento escolar oficial vem se tornando objeto de discussão e reflexão de pesquisadores e professores e, em função dos acontecimentos do século XXI, principalmente aqueles provocados pelas inovações tecnológicas, inscrevendose Martin Barbero (2005) no rol daqueles que participam desse diálogo.

Segundo esse autor, os saberes e o conhecimento em geral vêm progressivamente ocupando o lugar da força muscular humana e das máquinas, de tal forma que nos deparamos com uma profunda mutação no modo de circulação do saber, escapando este dos lugares sagrados que o continham e também do controle dos especialistas.

Em outras palavras, diz ele, no caso específico dos saberes escolares, isso significa que os mesmos não se centram apenas nos livros nem na própria escola, sendo necessário ir além da ideia fundadora da cultura ocidental que delega ao livro o papel de ordenador dos saberes. Torna-se necessário entender a complexidade dos processos subjacentes aos modelos de aprendizagem que, diferentemente de uma cultura grafocêntrica, focada na linearidade dos movimentos, deslocam e 
destemporalizam os saberes, fazendo entrar em cena os meios audiovisuais, o computador, entre outras inovações.

Propõe Barbero uma transversalidade constituída de saberes múltiplos, desde aqueles da ordem do lógico-simbólico, construtores de uma mentalidade em consonância com o mundo das tecnologias informáticas e das lógicas que essas requerem, passando por aqueles de natureza histórica, que possibilitam desnaturalizar o obvio, evitando qualquer tipo de determinismo, desestabilizando o presente para criar horizontes e projetos futuros e, finalmente, chegando aos saberes estéticos, os saberes da sensibilidade, incluídos nas formas do expressivo, que remetem para o corpo, para emoção, para o prazer. Esse conjunto de saberes amplia o campo de atuação docente de forma a dar respostas às novas exigências da vida social e à construção da cidadania.

Ao falarmos da formação do professor de línguas, insere-se a necessidade de que seja pensada ou repensada a noção de linguagem, subsidiaria da prática docente na sala de aula.

\section{Sobre uma pedagogia dos multiletramentos}

A pedagogia dos multiletramentos defendida pelo Grupo de Nova Londres é fruto dos desdobramentos de discussões entre dez educadores - Courtney Cazden, Bill Cope, Norman Fairclough, James Gee, Mary Kalantzis, Gunther Kress, Allan Luke, Carmen Luke, Sarah Michaels e Martin Nakata - que se encontraram em Nova Londres, Estados Unidos, em 1994, com o objetivo de debater os propósitos da educação de forma mais geral, assim como a relação estreita destes com a pedagogia do letramento. Como primeiro fruto dessas discussões, esse Grupo, composto por pesquisadores dos Estados Unidos, Reino Unido e Grã Bretanha, publicou na Harvard Educational Review o artigo seminal $A$ Pedagogy of Multiliteracies: Designing Social Futures [A pedagogia dos multiletramentos: desenhando futuros sociais] (CAZDEN, COPE et al, 1996) e, quatro anos mais tarde, a coletânea Multiliteracies: Literacy Learning and the Design of Social Futures [Multiletramentos: pedagogia do letramento e o desenho de futuros sociais] (COPE, KALANTZIS, et al, 2000), que, além de uma reedição do artigo de 1996, inclui dezesseis capítulos escritos por integrantes do Grupo que se reuniu inicialmente em Nova Londres e de outros educadores, interessados em redesenhar suas práticas em uma perspectiva de multiletramentos, que se integraram ao 
Grupo ao longo desse período ${ }^{1}$.

Contrapondo-se a uma pedagogia do "mero letramento" (CAZDEN, COPE et al., 1996, p.64), ou seja, ao foco de diferentes abordagens $^{2}$ que têm informado as discussões sobre letramento na linguagem escrita e em uma língua nacional única concebida como um conjunto estável de regras, o Grupo de Nova Londres toma como princípio fundador a multiplicidade de linguagens que opera no processo de construção de significados na contemporaneidade para propor uma pedagogia dos multiletramentos. Segundo o Grupo, o termo multiletramentos foi "escolhido para descrever dois importantes argumentos que se colocam diante da ordem cultural, institucional e global emergente: a multiplicidade de canais de comunicação e media e a importância crescente da diversidade linguística e cultural (CAZDEN, COPE et al., 1996, p. 63)"2.

A partir da premissa de que um novo letramento multimodal é fundamental para a nossa inserção em um mundo onde significados emergem de forma cada vez mais translocal, multicultural e híbrida

\footnotetext{
1 Com o objetivo de mapear os principais interesses que marcariam uma etnografia do letramento na atualidade, Street (2009) localiza as diferentes perspectivas sobre letramentos em quatro tradições: letramento e aprendizagem, abordagens cognitivas do letramento, abordagens situadas em práticas sociais e letramento e texto.
}

(COPE; KALANTZIS, 2000), o Grupo de Nova Londres defende que a educação se volte para formação de designers de significados capazes de compreender, produzir e transformar significados linguísticos, visuais, de áudio, gestuais e espaciais no processo de desenhar novos futuros sociais no trabalho, na esfera pública e na comunidade.

Atentos ao fato de que as práticas do novo capitalismo global construídas discursivamente têm impactos na nossa vida profissional, pública e pessoal, o Grupo de Nova Londres (2000) ressalta as principais mudanças que temos vivenciado nesses três campos da vida social para a definição do "o que" e "como" da pedagogia dos multiletramentos. Em relação ao "o que", propõem a adoção de uma metalinguagem dos multiletramentos baseada no conceito de design em que "professores e gerentes são vistos como designers de processos de aprendizagem e ambientes, não como chefes ditando o que aqueles sob sua responsabilidade devem fazer (GRUPO DE NOVA LONDRES, 2000, p.19: Teachers and managers are

\footnotetext{
2 Texto no original: "We decided that the outcomes of our discussions could be encapsulated in one word

- multiliteracies - a word we chose to describe two important arguments we might have with emerging cultural, institutional, and global order: the multiplicity of communication channels and media, and the increasing saliency of cultural and linguistic diversity."
} 
seen as designers of learning processes and environments, not as bosses dictating what those in their charge should think or do)". Nesse sentido, qualquer atividade semiótica é considerada uma questão de design a ser tratada levando-se em consideração três aspectos: desenhos disponíveis (recursos para construção de significados), desenho (trabalho realizado nos processos semióticos a partir dos desenhos disponíveis) e o redesenho (recursos produzidos e transformados durante $\mathrm{o}$ desenho).

O "como" da pedagogia dos multiletramentos, por sua vez, busca justificar a reforma pedagógica proposta, marcando o posicionamento epistemológico do grupo de que "a mente humana é corporificada, situada e social (GRUPO DE NOVA LONDRES, 2000, p.30: Our view of mind, society and learning is based on the assumption that the human mind is embodied, situated and social)". Fundamentados nessa concepção, a proposta defendida é de que a pedagogia dos multiletramentos seja objeto de constante reformulação a partir de quatro componentes não lineares, que se interrelacionam, e não hierarquizados.

3 No original: "Critical Language Awareness" (FAIRCLOUGH, 1995/2010).

${ }^{4}$ No original: "Different lifeworlds" (CAZDEN, COURTNEY et al., 1996; GRUPO DE NOVA LONDRES, 2000).
Reproduzimos esses elementos no quadro adiante.

Embora compartilhemos a visão de Fairclough (1995/2010) de que a pedagogia dos multiletramentos se situa em uma perspectiva crítica de conscientização sobre a linguagem ${ }^{3}$ na medida em que se constrói a partir da problematização das relações de trabalho, de cidadania e de estilos de vida particulares $^{4}$ no novo capitalismo global para pensar no (re)desenho de definições de forma a dar conta da multiplicidade de semioses e estilos de vida na contemporaneidade, percebemos, por outro lado, que, em diversos aspectos, a pedagogia desenhada pelo Grupo de Nova Londres legitima determinadas ordens do discurso $^{5}$ desse mesmo capitalismo que critica. Essa legitimação aparece, por exemplo, na aproximação entre professores e gerentes na definição da concepção de designer e na ênfase maior que é dada na proposta inicial do Grupo na preparação para o mercado de trabalho (prática situada), ainda de o desenvolvimento de uma metalinguagem que permita o enquadre crítico de todas as práticas também ser apontado.

\footnotetext{
${ }^{5}$ Fairclough (1995/2010, p.555) define ordem do discurso como a rede de práticas sociais descritas a partir de perspectivas discursivas singulares, consistindo de discursos e gêneros em situações específicas entre si.
} 
Quadro 1 - Componentes que integram o "Como" da Pedagogia dos Multiletramentos (GRUPO DE NOVA LONDRES, 2000, p.35) ${ }^{1}$

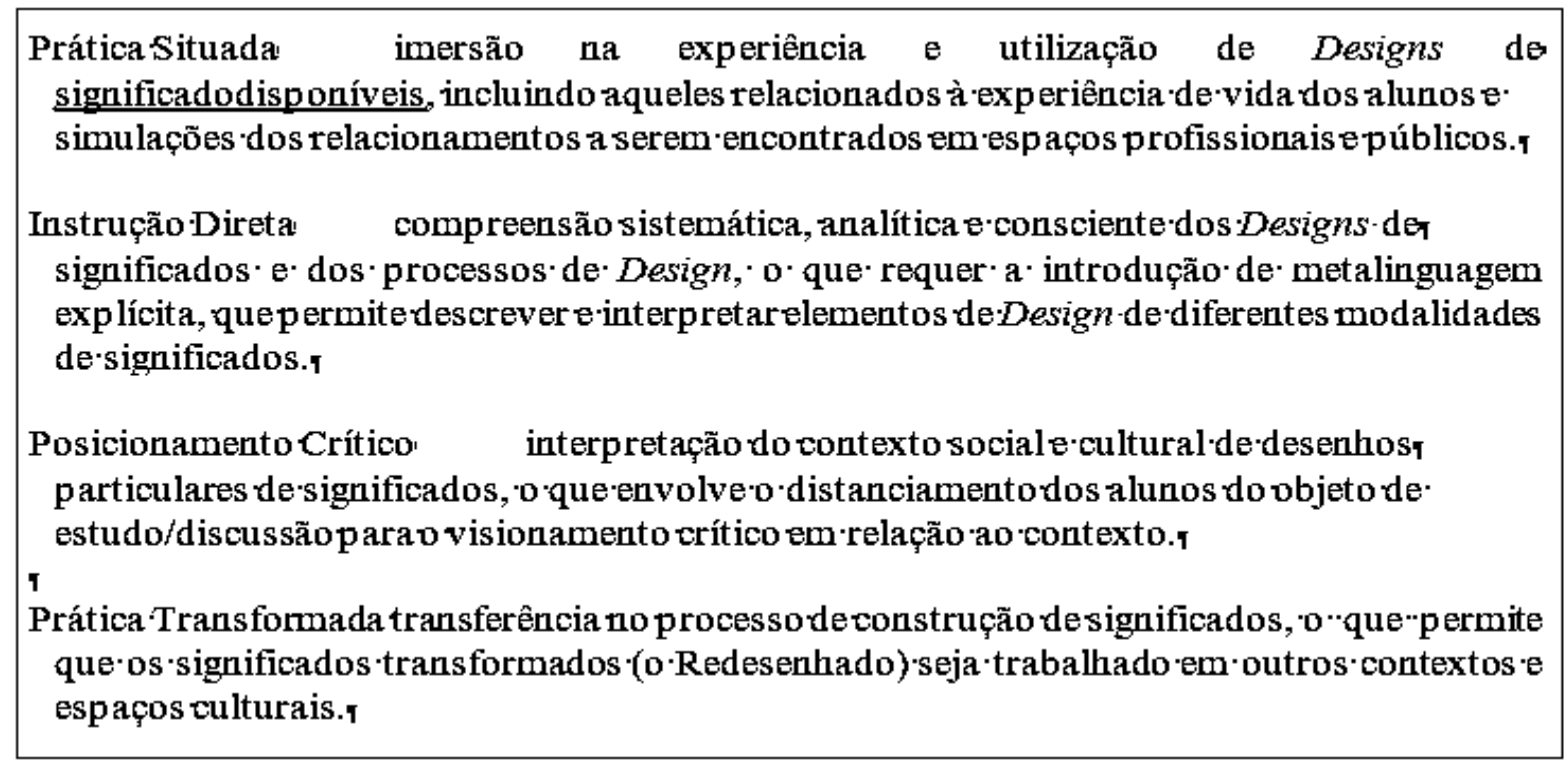

Vale ressaltar ainda que a pedagogia dos multiletramentos foi pensada como alternativa educacional para responder às "dramáticas mudanças econômicas globais" que vivemos "à medida que novas teorias e práticas de gerenciamento emergem no mundo desenvolvido" (GRUPO DE NOVA LONDRES, 2000, p.10)1.

Por ter como seu objeto enunciados constantemente (re)situados em processos de (inter)ações inscritos na singularidade de eventos concretos, capazes de transformar e serem transformados pelas nossas atitudes responsivas (e responsáveis) à vida e a outrem, entendemos que concepções de linguagem do Círculo de Bakhtin podem conversar com aquelas de formação de professores, linguagem e multiletramentos defendidas ao longo desse artigo para esboçar paisagens educacionais mais responsivas à contemporaneidade.

\section{Por uma (trans)formação de professores de linguagens como ato responsável}

Refletir sobre práticas educacionais responsivas à contemporaneidade é indissociável da reflexão acerca do processo de formação inicial e continuada

\footnotetext{
${ }^{1}$ Texto original: "Situated Practice - immersion in experience and the utilization of available designs of meaning, including those from the students' lifeworlds and simulations of the relationships to be found in workplaces and public spaces; Overt Instruction - systematic, analytic, and conscious understanding of Designs of meaning and Design processes. In the case of Multiliteracies, this requires the introduction of explicit metalanguages, which describe and interpret the Design elements of different modes of meaning; Critical Framing - interpreting the social and cultural context of particular designs of meaning. This involves the students' standing back from what they are studying and viewing it critically in relation to its context; Transformed Practice - transfer in meaning-making practice, which puts the transformed meaning (the Redesigned) to work in other contexts or cultural sites."

1 Texto original: "We are living through a period of dramatic global economic change, as new business and management theories and practices emerge across the developed world."
} 
de professores, pois sem que transformações ocorram na forma de pensar e agir de professores e formadores de professores, as práticas de letramento tradicionais continuarão a ser as únicas legitimadas nas escolas e universidades, contribuindo para aumentar a distância entre as práticas educacionais e a vida e validar processos de marginalização e exclusão sociais.

Partindo da premissa de que conceitos da filosofia da linguagem do Círculo de Bakhtin ressignificados em diálogos profícuos com concepções de formação de professores, linguagem e letramento no âmbito da Linguística Aplicada podem indicar rotas capazes de (trans)formar educadores mais responsivos às práticas de construção de significados na sociedade contemporânea, recorremos a esses diálogos como possibilidades epistemológicas para refletir sobre as duas questões postuladas na Introdução desse artigo:

1. Como tornar-se professor em uma sociedade marcada por rupturas, mudanças?

2. Como realizar um trabalho docente com as linguagens no sentido de contribuir com a construção de sujeitos capazes de transitar, compreendendo, interpretando e respondendo, a partir de posicionamentos valorados, (a)os discursos produzidos e circulantes nessa sociedade.

Em um mundo em que o desenvolvimento tecnológico possibilita a hibridização de linguagens e culturas em processos complexos de (re)criação de significados, parece-nos mais premente do que nunca que professores se tornem analistas dos discursos capazes de engajar os alunos em práticas de análise e (re)construção de significados pautadas nos multiletramentos, ou seja, na articulação entre múltiplas modalidades semióticas e múltiplas culturas. Uma articulação tal pressupõe inter-relações constantes entre as práticas de letramento escolares e àquelas da vida em processos de semiotização de atos éticos.

Ao destacar nosso não álibi perante atos sempre inscritos e avaliados na singularidade do existir evento, o ensaio Por uma filosofia do ato responsável (BAKHTIN, 2010) nos leva a pensar que uma educação responsável e responsiva à contemporaneidade não permite que se apartem os conhecimentos científicos de suas implicações éticas sobre as formas de vida.

[...] É necessário reconduzir a teoria em direção não a construções teóricas e à vida pensada por meio destas, mas ao existir como evento moral, em seu cumprir-se real - à razão prática - o que, responsavelmente, faz quem quer que conheça, aceitando a responsabilidade de cada um dos atos de sua cognição em sua integralidade, 
isto é, na medida em que o ato cognitivo como meu ato faça parte, com todo o seu conteúdo, da unidade da minha responsabilidade, na qual e pela qual eu realmente vivo e realizo atos (BAKHTIN, 2010, p.58).

Educar como ato responsável pressupõe, portanto, a consciência de que nossas opções epistemológicas são sempre de natureza ideológica e política e tem implicações éticas na vida de outrem. Nesse sentido, embora a opção pela supremacia do conhecimento científico em uma orientação epistemológica que Santos (2007) classifica como "sociologia das ausências" possa nos parecer mais segura e confortável, a assunção de que o "ato cognitivo como meu ato faça parte, com todo o seu conteúdo, da unidade da minha responsabilidade" nos leva a sair da nossa zona de conforto para nos questionarmos sobre as implicações éticas de tal orientação.

Partindo da crítica a esse modo de pensar a produção de conhecimento na modernidade clássica marcado pela linearidade histórica e homogeneização das diferenças na busca por verdades universais e generalizações baseadas no rigor científico, Santos (2007) propõe sua substituição por uma perspectiva denominada "ecologia dos saberes". Caracterizada pelo diálogo entre o conhecimento científico e outras formas de saberes, pelo rompimento da temporalidade histórica e por práticas que promovem a "descolonização" das mentes a partir da compreensão dos mecanismos que produzem desigualdades, a perspectiva proposta por Santos indica um caminho possível para (trans)formar professores na contemporaneidade capazes de semiotizar atos éticos.

$\mathrm{Na}$ esteira do que propõe Santos (2007), outros pesquisadores interessados na formação docente (NÓVOA, 1995; TARDIFF, 2000; BARBERO, 2005; CELANI, 2010,

entre outros) destacam a complexidade deste processo marcado por incertezas, conflitos, rupturas e embates entre diferentes tipos de saberes: curriculares, profissionais e da experiência (TARDIFF, 2000), um processo de desestabilização e, portanto, de (trans)formação. Se tomarmos a docência como resposta contextualizada no sentido proposto por Nóvoa (2005), parece-nos inevitável pensar nos papéis do professor em uma sociedade onde a escola deixou há muito de ser a guardiã do conhecimento e o livro o seu principal meio de acesso (BARBERO, 2005). Mais do que nunca os professores são desafiados a sair da zona de conforto propiciada pelo rigor científico e abrir espaços em suas práticas para explorar os desdobramentos éticos de significados situados construídos cada vez mais através de múltiplas linguagens. 
Por focar a multiplicidade e hibridação de linguagens e culturas convocadas pela sociedade contemporânea em processos de construção de significados assim como as implicações éticas de tais processos no mundo do trabalho, no pluralismo cívico e nos estilos de vida, a pedagogia dos multiletramentos constrói-se no imbricamento entre teoria e ato ético inscritos no existir-evento, representando, portanto, uma alternativa epistemológica para um trabalho docente com as linguagens no sentido de contribuir com a construção de sujeitos capazes de transitar, compreendendo, interpretando e respondendo, a partir de posicionamentos valorados, (a)os discursos produzidos $e$ circulantes nessa sociedade (questão 2).

Ao propor a noção de design como o elemento central no processo de construção de significados e enfatizar as múltiplas modalidades de designs mobilizados nesse processo linguístico, visual, gestual, espacial, auditivo etc., a pedagogia dos multiletramentos nega quaisquer possibilidades de trabalho abstrato com a linguagem e toma os sentidos refratados por enunciados concretos sempre (re)situados em contextos sócio, histórico e culturalmente específicos como o instrumento de trabalho do

2 Texto original: "We propose to treat any semiotic activity, including language to produce and consume texts as a matter of design [...]" professor.

A compreensão do Grupo de Nova Londres (2000, p. 20) de design como "qualquer atividade semiótica, incluindo a utilização da língua para consumir e produzir textos" $" 2$ através de três processos: desenhos disponíveis, desenho e redesenho, aproxima o tratamento dado às linguagens pelo Grupo da sugestão de Bakhtin/Voloshinov de que:

[...] a psicologia do corpo social deve ser estudada de dois pontos de vistas diferentes: primeiramente, do ponto de vista do conteúdo, dos temas que aí se encontram atualizados num dado momento do tempo; e, em segundo, do ponto de vista dos tipos e formas de discurso através dos quais estes temas tomam forma, são comentados, se realizam, são experimentados, são pensados etc.[...] (1999, p. 42).

Tal aproximação ocorre na assunção de que os designs para o Grupo de Nova Londres e os gêneros do discurso para o Círculo de Bakhtin são constantemente (re)atualizados e (re)desenhados a partir das atitudes responsivas de comunidades específicas em momentos históricos situados. É, portanto, o desenvolvimento histórico e cultural levado a cabo pela agência humana nas diferentes comunidades que permite a transformação dos significados construídos através do redesenho constante dos tipos e formas do 
discurso (designs) disponíveis. Faz sentido, portanto, que as formas de construção de significados realizados através da multimodalidade e da hibridação de gêneros e as possibilidades de (re)desenhar significados mais éticos constituam o objeto de uma pedagogia responsiva à contemporaneidade.

Apesar das concepções de gêneros do discurso/texto terem sido convocadas na contemporaneidade para lidar com as privações sofridas no contexto educacional (ROJO, 2008), o tratamento que tem sido dado ao gênero, especialmente nas teorias que operam com a concepção de gêneros textuais, tem focado principalmente as características estáveis do gênero e o desenvolvimento de capacidades/competências que propiciem a compreensão e produção de gêneros orais e escritos que circulam no mundo social.

Uma das implicações desse tipo de tratamento para as práticas de letramento na escola tem sido, com bastante frequência, o deslocamento do gênero dos contextos micro e macro linguísticos que interagem na construção dos significados para focar, de forma abstrata, nas características estáveis que definem notícias, tiras em quadrinho, receitas, editorial, blogs etc. Um outro, e talvez mais sério, desdobramento é que, ao deixar de olhar para o modo como os gêneros se intercalam e hibridizam com outros gêneros e semioses em processos constantes de (re)desenhos de significados, tal tratamento pode acabar por contribuir simplesmente para (re)produção de gêneros legitimados pela escola, deixando pouco ou nenhum espaço para as inovações e desestabilizações que processos de mistura e transgressão imprimem aos textos da contemporaneidade e, portanto, para um posicionamento crítico em relação aos significados construídos às margens do que a escola valida como práticas de letramento aceitáveis.

Ao propor uma reforma pedagógica em que as práticas de letramentos se orientam para o redesenho de futuros sociais através da imersão em experiências situadas, do desenvolvimento de uma metalinguagem para descrever e interpretar diferentes modalidades de significados, do visionamento crítico dos contextos onde significados são construídos e da transformação desses significados, a pedagogia dos multiletramentos abre espaços para processos de formação de professores e de ensino-aprendizagem voltados para o acontecimento, o irrepetível, o que é da ordem do discursivo e cujo funcionamento não se dá pela estrutura, mas em rede. Apresenta, portanto, instrumentos pedagógicos abertos ao plurilinguismo social. 


\section{CONCLUSÃO}

Inspiradas pelos diálogos que a filosofia do ato responsável de Bakhtin (2010) nos levou a estabelecer com perspectivas de formação de professores no âmbito da Linguística Aplicada, buscamos neste artigo esboçar uma reflexão sobre os significados de educar como ato responsável, destacando o papel fundamental dos professores e suas (trans)formações no redesenho de uma pedagogia mais responsiva à contemporaneidade.

Para delinear essa reflexão o caminho epistemológico que elegemos foi relacionar concepções da filosofia da linguagem do Círculo de Bakhtin com noções sobre saberes docentes, linguagem e língua, multiletramentos e formação de professores de linguagens como ato responsável. Fruto dos diálogos que temos estabelecido entre os saberes teóricos e práticos no fluxo de nosso existir evento como professoras, formadoras e linguistas aplicadas, essa rota epistemológica culminou na nossa defesa da pedagogia de multiletramentos como possibilidade para redesenhar paisagens educacionais mais responsivas à contemporaneidade.

Partindo da negação da existência

1 Texto original: "The role of pedagogy is to develop an epistemology of pluralism that de uma língua nacional padrão e universal para a defesa de uma pedagogia do acesso cuja função "é desenvolver uma epistemologia do pluralismo que forneça acesso (ao capital simbólico) sem que as pessoas tenham que apagar ou deixar para trás suas diferentes subjetividades" (GRUPO DE NOVA LONDRES, 2000, p.18) ${ }^{1}$, a pedagogia dos multiletramentos parece conversar com a concepção dialógica e plurilíngue da linguagem do Círculo de Bakhtin para a compreensão e transformação dos significados multissemioticamente refratados nas práticas de letramento da contemporaneidade. Representa, portanto, uma possibilidade, para a busca de respostas educacionais eticamente responsáveis e responsivas à contemporaneidade.

Já que respostas educacionais são sempre situadas e contextualizadas, o caminho trilhado constitui um dentre muitos (re)desenhos possíveis. No entanto, seja qual for o desenho escolhido, vale enfatizar que uma educação responsável é sempre responsiva à vida, insere-se sem álibi no existir-evento para ressignificá-lo e transformá-lo.

provides access without people having to erase or leave behind different subjectivities 


\section{REFERÊNCIAS}

BAKHTIN, M. M. Para uma filosofia do ato responsável. Trad. aos cuidados de Valdemir Miotello e Carlos Alberto Faraco. São Carlos: Pedro \& João Editores, 2010.

BAKHTIN, M. O discurso no romance. In: BAKHTIN, M. Questões de literatura e de estética: A teoria do romance. 2 ed. Trad. Aurora Fornoni Bernardidi et al. São Paulo: Hucitec, 1990.

\section{BAKHTIN, M. (VOLOCHÍNOV).}

Marxismo e filosofia da linguagem.

Problemas fundamentais do método sociológico na ciência da linguagem. 10. ed. Trad. Michel Lahud e Yara Frateschi Vieira. São Paulo: Hucitec, 1999.

BAUMAN, Z. Modernidade líquida. Trad. Plínio Dentzien. Rio de Janeiro: Zahar, 2001.

BLOMMAERT, J. Citizenship, Language and Superdiversity: Towards Complexity. Working Papers in Urban Language and Literacies. Paper 95. Tillburg University, p.2- 5, 2012.

CASTELLS, M. A sociedade em rede: do conhecimento à ação política. Lisboa: Editora da Imprensa Nacional, Casa da Moeda, 2006.

CAZDEN, C.; COPE, B.; FAIRCLOUGH, N.; GEE, J.; et al. A Pedagogy of Multiliteracies: Designing Social Futures. Harvard Educational Review; n. 66.1, p.6092, Spring 1996.

CELANI, M. A. A. Concepções de linguagem de professores de inglês e suas práticas em sala de aula. In CELANI, M. A. A. (Org.). Reflexões $e$ ações (trans)formadoras no ensino-aprendizagem de línguas. Campinas: Mercado de Letras, 2010, p.129-140.

COPE, B.; KALANTZIS, M. (Ed.). Multiliteracies: Literacy Learning and the
Design of Social Futures. Routledge: Psychology Press, 2000.

COPE, B.; KALANTZIS, M. Changing the Role of Schools. In COPE, B.; KALANTZIS, M. (Ed.). Multiliteracies: Literacy Learning and the Design of Social Futures. Routledge: Psychology Press, 2000, p.121-148.

FAIRCLOUGH, N. Critical Language Awareness and Self-Identity in Education. In: Critical Discourse Analysis: The Critical Study of Language. Longman, 2010, p.531- 543.

FARACO, C.A. Linguagem \& Diálogo: as ideias linguísticas do Círculo de Bakhtin. São Paulo: Parábola Editorial, 2009.

GATTI, B. Formação de professores no Brasil: características e problemas. Educação e Sociedade, Campinas, v.31, n.113, 2010, p.1355-1379.

GERALDI, J. W. A diferença identifica. A desigualdade deforma. Percursos bakhtinianos de construção ética e estética. In: FREITAS, M. T; JOBIM, S. e KRAMER, S. Ciências Humanas $e$ Pesquisa: leituras de M. Bakhtin. São Paulo: Cortez Editora, 2003, p.39-56.

GRUPO DE NOVA LONDRES. A Pedagogy of Multiliteracies: Designing Social Futures. In COPE, B.; KALANTZIS, M. (Ed.). Multiliteracies: literacy learning and the design of social futures. Routledge: Psychology Press, 2000, p.9-37.

HALL, S. The Centrality of Culture: Notes on the Cultural Revolutions of our Time. In: THOMPSON, K. (ed.). Media and Cultural Regulation. London: Thousand Oaks; New Delhi: The Open University; SAGE Publications, 1997, p. 209-236.

KUMARAVADIVELU, B. A Linguística Aplicada na era da globalização. In: MOITA LOPES, L. P. (Org.). Por uma 
linguística aplicada indisciplinar. São Paulo: Parábola, 2006, p.129-148.

LEMKE, J. L. Letramento metamidiático: transformando significados e mídias. Trabalhos em Linguística Aplicada, Campinas, n. 49.2, p.455-479, 2010.

MARTIN-BARBERO, J. Uma escuela cuidadana para uma ciudad-escuela. Cátedra de Pedagodia: Bogotá uma grande escuela. 2004. www.mediaciones.net. Acesso em 28 de agosto de 2010.

Saberes hoy: transversalidades, competências y diseminaciones. www.mediaciones.net. Acesso em $10 \mathrm{de}$ maio de 2013.

MIGNOLO, W. Histórias locais/projetos globais: colonialidade, saberes subalternos $e$ pensamento liminar. Belo Horizonte: Editora da UFMG, 2003.

MOITA LOPES, L. P. Da Linguística Aplicada como lugar de construir verdades contingentes: sexualidades, ética e política. Gragoatá, v. 27, p.33-50, 2010.

(Org.) Por uma linguística indisciplinar. São Paulo: Parábola Editorial, 2006.

Como e porque teorizar o português: recurso comunicativo em sociedades porosas e em tempos híbridos de globalização cultural. In: MOITA LOPES, L. P. (Org.). O português no século XXI. São Paulo: Parábola, 2013, p.101-119.

NÓVOA, A. Vidas de professores. Porto: Porto Editora, 1995.

OLIVEIRA, M. B. F de. Formação de professores de língua materna e a sociedade do conhecimento: discutindo concepções de linguagem. In: ZOZZOLI, R. M. D.; OLIVEIRA, M. B. F. de (Org.). Leitura, escrita e ensino. Maceió: Editora da Universidade Federal de AlagoasEDUFAL, 2008, p.171-190.

PENNYCOOK, A. Uma Linguística Aplicada transgressiva. In: MOITA LOPES, L. P. (Org.) Por uma linguística indisciplinar. São Paulo: Parábola Editorial, 2006, p.67-84.

PINTO, J. P. Da língua objeto à práxis linguística: desarticulações e rearticulações contra hegemônicas. Linguagem em Foco, Fortaleza, v2, n.2, p.69-84, 2010.

PRENSKY, M. Teaching Digital Natives: Partnering for Real Learning. Corwin Press, 2010.

ROJO, R. H. R. Escola conectada: os multiletramentos e as TICS. São Paulo: Parábola, 2013.

Gêneros do discurso/texto como objeto de ensino de línguas: um retorno ao trivium? In: SIGNORINI, I. [Re]Discutir texto, gênero e discurso. São Paulo: Parábola Editorial, 2008, p.73-108.

SACRISTAN, J.G. Tendências investigativas na formação de professores. In: PIMENTA, S. G. e GHEDIN, E. (Orgs.). Professor reflexivo no Brasil: gênese e crítica de um conceito. São Paulo: Cortez Editora, 2002, p.21-28.

SANTOS, B. Renovar a teoria crítica $e$ reinventar a emancipação social. São Paulo: Boitempo, 2007.

SEGANFREDO, L. et al. Face a face com Nóvoa. Formação inicial e continuada. Entrevista com Antonio Nóvoa. Revista de Letras. Norteamentos, Mato Grosso, v.5.n.10, p.2-13, 2012.

SIGNORINI, I. Letramentos multihipermidiáticos e formação de professores de língua. In: SIGNORINI, I. e FIAD, R. S. (Orgs.). Ensino de língua: das reformas, das inquietações e dos desafios. Belo 
Horizonte: Editora da UFMG, 2012, p.282303.

STEHR, N. Desigualdade de classe à desigualdade de conhecimentos. Revista Brasileira de Ciências Sociais, vol.15, n.42, p.101-112, 2000.

STREET, B. Ethnography of Writing and Reading. In: TORRANCE, N.; OLSON, D. R. The Cambridge Handbook of Literacy. Cambridge: Cambridge University Press, 2009. p.329-345.

SZUNDY, P. T. C. Educação como ato responsável: a formação de professores de linguagens à luz da filosofia da linguagem do Círculo de Bakhtin. Trabalhos em Linguística Aplicada, Campinas, n. 53.1, p.13-32, 2014.

TARDIFF. M. Saberes profissionais dos professores e conhecimentos universitários: elementos para uma epistemologia da prática profissional dos professores e suas consequências. Revista Brasileira de Educação, n.13, 2000, p.524.

VOLOSHINOV, V. El signo ideológico y la filosofía del lenguaje. Trad. Rosa María Rússovich, a partir do inglês [1973]. Buenos Aires: Ediciones Nueva Visión, 1976 